\title{
ANTERIOR CLINOID PROCESS AND OPTIC STRUT- A MORPHOMETRIC STUDY
}

\author{
Nirupma Gupta1 ${ }^{1}$ Abhilasha Priya ${ }^{2}$ \\ 1 Professor and HOD, Department of Anatomy, School of Medical Sciences and Research, Sharda University, Greater Noida, \\ Uttar Pradesh, India. \\ ${ }^{2}$ Assistant Professor, Department of Anatomy, School of Medical Sciences and Research, Sharda University, Greater Noida, \\ Uttar Pradesh, India.
}

\begin{tabular}{l}
\hline ABSTRACT \\
BACKGROUND \\
During surgery for various neoplastic and vascular neurosurgical diseases in the suprasellar and parasellar region, a detailed \\
morphometric knowledge of anterior clinoid process and optic strut (a bony pillar joining body of sphenoid to the lesser wing of \\
sphenoid) is required. \\
So, the present study aims at providing the morphometric data of these bony landmarks and also aims at providing the location \\
of optic strut in relation to anterior clinoid process.
\end{tabular}

\section{MATERIALS AND METHODS}

In the present descriptive study, 30 dry skulls of North Indian adults were used from the Department of Anatomy. Following morphometric measurements were done on dry skulls using manual calipers in mm and recorded. Photographs of ACP, OS and the relation between both were taken using digital camera. 1) Length of ACP of both the sides; 2) Length of OS of both the sides; 3 ) Relation of location of OS with ACP. Statistical analysis was done to find out the values like mean and standard deviation and the results were tabulated.

\section{RESULTS}

Maximum length of ACP on the left side was $15 \mathrm{~mm}$ and minimum length recorded was $9 \mathrm{~mm}$. Mean \pm SD was calculated to be $11.61 \pm 2.07$. Maximum length of ACP on the right side was $13.5 \mathrm{~mm}$ and the minimum recorded length was 9.6. Mean \pm SD was calculated to be $11.1 \pm 1.49$ on the left side. Length of optic strut was measured from the side of body of sphenoid to the ACP. Maximum length of optic strut on the left side was $6.0 \mathrm{~mm}$ and the minimum length was $2.0 \mathrm{~mm}$. Mean \pm SD was calculated to be $3.97 \pm 1.3$. On the right-side maximum length was 6.1 and minimum length was same as on the right side, i.e. $2 \mathrm{~mm}$. Mean \pm SD was calculated to be $3.94 \pm 1.0$. Optic strut was located in anterior $1 / 3$ of the anterior clinoid process.

\section{CONCLUSION}

Morphometric knowledge of anterior clinoid process and optic strut is useful to surgeons operating in the supra/ parasellar region. It will help the surgeons in careful dissection in this area preventing damage to important structures like optic nerve, ophthalmic artery, internal carotid artery etc.

\section{KEY WORDS}

Anterior Clinoid Process, Optic Strut, Cavernous Sinus.

HOW TO CITE THIS ARTICLE: Gupta N, Priya A. Anterior clinoid process and optic strut- a morphometric study. J. Evolution Med. Dent. Sci. 2018;7(32):3577-3580, DOI: 10.14260/jemds/2018/803

\section{BACKGROUND}

In the parasellar region, Anterior Clinoid Process (ACP) with its supporting structures like Optic Strut (OS), medial part of lesser wing of the sphenoid and roof of the optic canal are certain bony landmarks related to important elements like the cavernous sinus, Internal Carotid Artery (ICA), Optic Nerve (ON) and the pituitary gland.(1)

The optic strut was first defined as the "Sphenoid Strut" by Jefferson in his 1936 radiographic study. This small bony pillar is described simply in the literature by Williams et al in

'Financial or Other Competing Interest': None.

Submission 25-06-2018, Peer Review 21-07-2018,

Acceptance 27-07-2018, Published 06-08-2018.

Corresponding Author:

Dr. Abhilasha Priya,

Assistant Professor, Department of Anatomy,

School of Medical Sciences and Research,

Sharda University, Knowledge Park-3

Greater Noida-201310, Uttar Pradesh, India.

E-mail: dr.abhilashapriya@gmail.com abhilasha.priya@sharda.ac.in

DOI: $10.14260 /$ jemds/2018/803
1989. Its size and angle have been studied by Parkinson in 1989.(2),(3),(4),(5)

Optic strut connects the body of sphenoid to the inferomedial aspect of base of anterior clinoid process and is removed during anterior clinoidectomy and optic canal decompression.(5) This is done for surgeries on tumours and aneurysms in the parasellar and suprasellar region to provide a better approach to the operating field primarily to the ICA, $\mathrm{ON}$ and to minimise the need for brain retraction. Moreover, superomedial margin of optic strut is significant in categorisation of intradural and extradural aneurysms.(6)

Although, much attention has been given to the anatomical variation of the ACP and its removal using intradural and extradural techniques, a paucity of data exists regarding the optic strut. In this morphometric study, we evaluate the anatomic variability that is position and thickness (Length) of the optic strut and length of the ACP and the location and relation of OS with ACP in human skulls of Indian origin to provide a data for neurosurgeons planning a procedure of parasellar region. 


\section{MATERIALS AND METHODS}

This is a descriptive study related with the morphometric measurement of 30 dry skulls of North Indian adults of either sex that were used from the set of bones available in the Department of Anatomy. Broken/ damaged/ diseased bones were discarded and not used in the study.

Following morphometric measurements were done on dry skulls using Vernier calipers in $\mathrm{mm}$ and recorded Photographs of ACP, OS and the relation between both were taken using digital camera.

1. Length of ACP on both the sides.

2. Length of OS on both the sides.

3. Relation of location of OS with ACP.

Statistical analysis was done to find out the values like mean and standard deviation and the results were tabulated. (Table 1 and 2) (Figure No. 1 and Figure No. 2). The data presented is the mean \pm standard deviation of the actual value. The data was analysed by unpaired student's t-test using SPSS software (version 21). The level of significant difference was $\mathrm{p}<0.05$.

\section{RESULTS}

The present study was conducted on a total of 60 sides in 30 dry adult skulls. Length of ACP was measured from its base to tip as shown by line AB in Figure 1. Maximum length of ACP on the left side was $15 \mathrm{~mm}$ and minimum length recorded was $9 \mathrm{~mm}$. Mean $\pm \mathrm{SD}$ was calculated to be $11.61 \pm 2.07$. Maximum length of ACP on the right side was $13.5 \mathrm{~mm}$ and the minimum recorded length was 9.6. Mean \pm SD was calculated to be $11.1 \pm 1.49$ on the left side (Table 1) (Fig. 1). No significant difference was observed amongst the sides.

Optic strut is a piece of bone located between upper side of body and lesser wing of sphenoid, which separates optic canal from medial side of superior orbital fissure.(7) Length of optic strut was measured from the side of body of sphenoid to the ACP (Fig. 2). Maximum length of optic strut on the left side was $6.0 \mathrm{~mm}$ and the minimum length was $2.0 \mathrm{~mm}$. Mean \pm SD was calculated to be $3.97 \pm 1.3$. On the right side, maximum length was 6.1 and minimum length was same as on the right side i.e. $2 \mathrm{~mm}$. Mean \pm SD was calculated to be $3.94 \pm 1.0$ (Table 2).

Location of optic strut in relation to ACP was also noted. OS was located in anterior $1 / 3$ of length of ACP in 18 out of 30 skulls $(60 \%)$ on the right side, whereas on the left side in 19 skulls it was located in anterior $1 / 3$ (63.33\%). On the right side, it was seen in middle $1 / 3$ of length of ACP in 9 skulls (30\%) and on the left side it was seen in 8 skulls $(26.67 \%)$. In only 3 skulls, OS was related to posterior $1 / 3$ of the length of the ACP on both the sides (10\%) (Table 3).

In one of the skulls we observed bilateral presence of two similar bony bar arising from the sides of the body of sphenoid towards the lesser wing of sphenoid bone, thus creating one extra foramina (Fig. 3). The length of the bars were $5 \mathrm{~mm}$ on right side and $6 \mathrm{~mm}$ on left side and the optic strut was placed in anterior $1 / 3$ of ACP on both sides (Fig. 3).

\begin{tabular}{|c|c|c|c|}
\hline $\begin{array}{c}\text { Length of ACP } \\
(\mathbf{m m})\end{array}$ & $\begin{array}{c}\text { Maximum } \\
\text { Value }\end{array}$ & $\begin{array}{c}\text { Minimum } \\
\text { Value }\end{array}$ & Mean \pm SD \\
\hline Left $(\mathrm{n}=30)$ & 15 & 9 & $11.61 \pm 2.07$ \\
\hline Right $(\mathrm{n}=30)$ & 13.5 & 9.6 & $11.1 \pm 1.49$ \\
\hline \multicolumn{4}{|c|}{ Table 1. Length of Anterior Clinoid Process on Right and } \\
Left Side \\
\hline
\end{tabular}

p-value $=0.491$

\begin{tabular}{|c|c|c|c|}
\hline $\begin{array}{c}\text { Length of OS } \\
(\mathbf{m m})\end{array}$ & $\begin{array}{c}\text { Maximum } \\
\text { Value }\end{array}$ & $\begin{array}{c}\text { Minimum } \\
\text { Value }\end{array}$ & Mean \pm SD \\
\hline Left $(\mathrm{n}=30)$ & 6.01 & 2.0 & $3.97 \pm 1.3$ \\
\hline Right $(\mathrm{n}=30)$ & 6.0 & 2.0 & $3.94 \pm 1.0$ \\
\hline \multicolumn{3}{|r|}{ Table 2. Measurement of Optic Strut } \\
\hline
\end{tabular}

$\mathrm{p}$-value $=0.463$

\begin{tabular}{|c|c|c|}
\hline $\begin{array}{c}\text { Attachment Position of OS in } \\
\text { relation to Length of ACP }\end{array}$ & $\begin{array}{c}\text { Right Side } \\
(n=30)\end{array}$ & $\begin{array}{c}\text { Left Side } \\
(n=30)\end{array}$ \\
\hline Anterior $1 / 3$ & $18(60 \%)$ & $19(63.33 \%)$ \\
\hline Middle $1 / 3$ & $9(30 \%)$ & $8(2.67 \%)$ \\
\hline Posterior $1 / 3$ & $3(10 \%)$ & $3(10 \%)$ \\
\hline
\end{tabular}

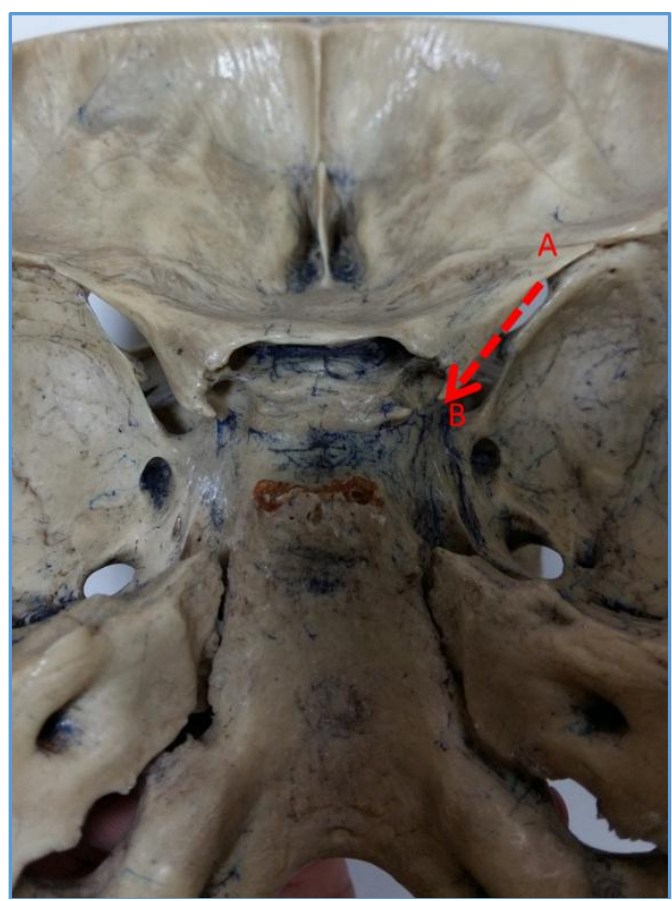

Figure 1. Showing Anterior Clinoid Process (ACP) and its Length (Red Dotted Line)

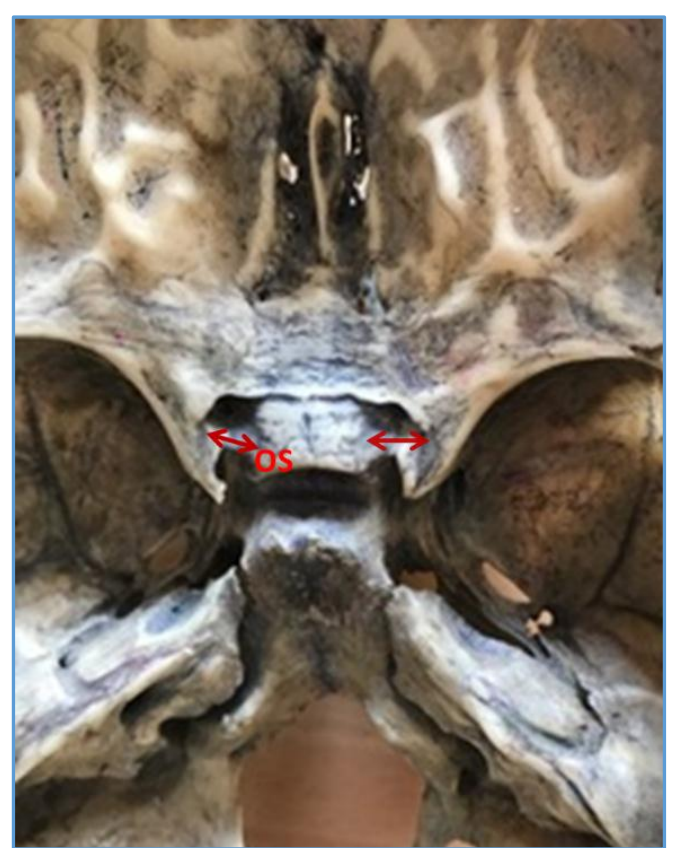

Figure 2. Showing Optic Strut (OS). A Bony Pillar extending from body of sphenoid to Lesser Wing of Sphenoid 


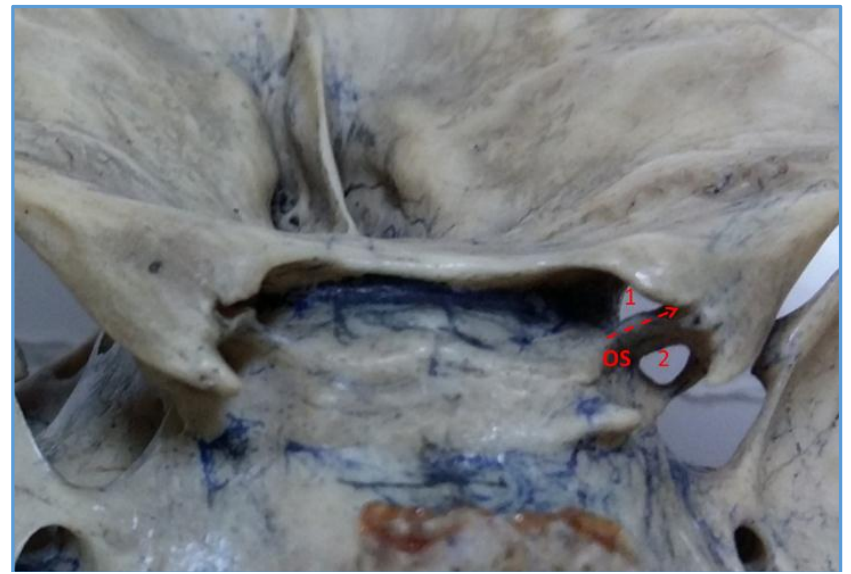

Figure 3. Showing bilateral presence of two similar bony bar arising from the sides of the body of sphenoid towards the Lesser Wing of Sphenoid creating an Extra Foramina

\section{DISCUSSION}

Safe and adequate surgical exposure is very important in operating various neoplastic and vascular neurosurgical lesions involving supra/ parasellar region, which could be skull base approaches like cranio-orbital, orbito-zygomatic and conventional craniotomies. But regardless of the location of the lesions and/ or surgical approach used, prominent body structures like ACP and OS pose difficulties for safe exposure by obscuring direct visualisation of important neurovascular structure like Internal Carotid Artery (ICA) and Optic Nerve (ON). Nevertheless, numbers of researchers have examined, yet the anatomy of this area remains varied and complex. ${ }^{(8)}$

In the study done by Hy Yeon Lee et al (1997) (3) on 73 dry skulls average length, basal width and thickness of ACP were $9.98 \pm 1.55,9.63 \pm 1.49$ and $5.32 \pm 1.07 \mathrm{~mm}$ respectively. However, in the present study ACP were lengthier with mean length of ACP on left and right side were $11.67 \pm 2.07$ and $11.1 \pm 1.49$. Gupta et al (2005) ${ }^{(9)}$ observed the mean length of ACP in Nepalese dry skulls on the right side as $10.74 \pm 2.37$ and on left side as $10.83 \pm 1.20$, which were slightly less than the length of ACP in North Indian dry skulls. A study by Kapur and Mehić,(7) on 200 dry skulls from Sarajevo and Bosnia average length was $9.9 \pm 1.6 \mathrm{~mm}$ and 8.7 $\pm 1.5 \mathrm{~mm}$ on right and $9.3 \pm 1.4$ and $8.3 \pm 2.1 \mathrm{~mm}$ on left side in males and females skulls respectively, which was less as compared to the North Indian skulls and comparable to a South Indian study done by Shahin Hunnargi et al (2008),(10) in their metrical and non-metrical study with mean length of $10.68 \pm 1.9 \mathrm{~mm}$ and $9.96 \pm 1.71 \mathrm{~mm}$ on right and left side respectively.

The morphology of the bone may be influenced by age, gender, geographical location, genetic factors and socioeconomical status.(9) This might account for the difference in length of ACP in Korean, Nepalese, South Indian, Bosnian and North Indian populations.

The optic strut represents a bony formation that connects the body of sphenoid bone and its lesser wing and separates optic canal from the medial part of the superior orbital fissure. Surgical procedures on cavernous sinus and suprasellar region demand total removal of the optic strut, which if not removed can lead to damage of optic nerve or internal carotid artery.(6) Moreover studies have suggested that optic strut to be removed before anterior clinoid process, otherwise anterior process bony fragments may damage optic nerve or internal carotid artery. In the present study a lengthier optic strut of $3.97 \pm 1.3 \mathrm{~mm}, 3.94 \pm 1.0 \mathrm{~mm}$ on right and left side was observed compared to Korean population.

In the present study, bilateral presence of two similar bony bars arising from the sides of the body of sphenoid towards the lesser wing of sphenoid bone thus creating one extra foramina below the optic canal. Such variation was not reported before in any other studies.

Presence of one extra bony bar arising from the sides of the body of sphenoid to the lesser wing of sphenoid can be attributed to the development and formation of the sphenoid bone. This bony bar is present beside the optic strut and is not connecting the ACP with the middle clinoid process. Sphenoid bone starts developing around $7^{\text {th }}-8^{\text {th }}$ weeks of gestational age as two parts; pre-sphenoidal part and a postsphenoidal part preformed in cartilage. There are six and eight ossification centres for pre-sphenoidal and postsphenoidal parts respectively, which fuse at around eight months in utero. Uniform cartilage persists after birth. Some parts of Sphenoid are connected by ligaments, which can ossify occasionally. This extra bony bar can be as a result of ossification of such ligament connecting different parts of sphenoid bone.(7,11)

As anterior clinoid process covers the roof of cavernous sinus and the paraclinoidal segment of the internal carotid artery, anterior clinoidectomy becomes mandatory in approaching cavernous sinus and in optic canal decompression so the parameters measured in the present study will guide in the careful dissection in that area.(5) Complications include damage to many important surrounding structures which includes internal carotid artery, optic nerve, ophthalmic artery, oculomotor nerve, pituitary gland, brain lobe etc. Knowledge of any variations of ACP may be useful in preventing damage to these structures.

\section{CONCLUSION}

The morphometric knowledge of the anterior clinoid process and optic strut is important for the surgeons operating in the parasellar region. There are many important neurovascular structures present in the parasellar region. The anatomical knowledge of ACP and OS may help the operating surgeons in reducing the damage to these neurovascular structures, thus reducing the complications.

\section{REFERENCES}

[1] Kiran SNA, Furtado SV, Hegde AS. How I do it: anterior clinoidectomy and optic canal unroofing for microneurosurgical management of ophthalmic segment aneurysms. Acta Neurochir (Wien) 2013;155(6):1025-9.

[2] Kerr RG, Tobler WD, Leach JL, et al. Anatomic variation of the optic strut: classification schema, radiologic evaluation, and surgical relevance. Journal of Neurological Surgery Part B, Skull Base 2012;73(6):424-9.

[3] Lee HY, Chung IH, Choi BY, et al. Anterior clinoid process and optic strut in Koreans. Yonsei Medical Journal 1997;38(3):151-4. 


\section{Jemds.com}

[4] Williams PL, Warwick R, Dyson M, et al. Gray's Anatomy. 37th edn. Edinburgh: Churchill Livingstone 1989: p. 373-7.

[5] Parkinson D. Optic strut: posterior root of sphenoid. Clin Anat 1989;2(2):87-92.

[6] Suprasanna K, Ravikiran SR, Kumar A, et al. Optic strut and para-clinoid region-assessment by multi-detector computed tomography with multiplanar and 3 dimensional reconstructions. Journal of Clinical and Diagnostic Research: JCDR 2015;9(10):TC06-TC09.

[7] Kapur E, Mehić A. Anatomical variations and morphometric study of the optic strut and the anterior clinoid process. Bosnian Journal of Basic Medical Sciences 2012;12(2):88-93.

\section{Original Research Article}

[8] Dagtekin A, Avci E, Uzmansel D, et al. Microsurgical anatomy and variations of the anterior clinoid process. Turk Neurosurg 2014;24(4):484-93.

[9] Gupta N, Ray B, Ghosh S. A study on anterior clinoid process and optic strut with emphasis on variations of carotico-clinoid foramen. Nepal Med Coll J 2005;7(2):141-4.

[10] Hunnargi S, Ray B, Pai SR, et al. Metrical and nonmetrical study of anterior clinoid process in South Indian adult skulls. Surg Radiol Anat 2008;30(5):4238.

[11] Dutta AK. Essentials of Human Anatomy-II. $3^{\text {rd }}$ edn. Calcutta: Current Books Interntaional 1999: p. 1-6. 